\title{
Development of a device adapted to perform the torch gas tungsten arc welding (GTAW) hardfacing using alloys in powder form
}

\author{
Paulo Cezar Moselli, Marcelo Falcão de Oliveira and João Roberto Sartori Moreno \\ Department of Mechanical and Materials Engineering, University Federal Thecnological of Paraná, Brazil.
}

Accepted 7 February, 2014

\begin{abstract}
This work was aimed at developing a device adapted to any gas tungsten arc welding (GTAW) torch, allows obtaining hard coatings by depositing alloys in powder form. For the purpose of verifying the feasibility of implementing this process, the results and parameters were compared with the plasma transferred arc (PTA) process. Due to good wear resistance was used as the substrate alloy SAE 1020 and alloy STELLITE 6 powder as depositor/hardfacing. Deposition rate, ideal flow of protection, dilution, micrographic and X-ray diffraction analysis results were raised to evaluate the proposed technique. The data showed a coating by the process GTAW pore-free and lowest dilution for both the GTAW and PTA process semi-automatics. However, gas consumption was lower for the GTAW process (8 L/min), due to reduced flow of the carrier gas. Microstructural analysis showed a microstructure similar for both processes, but the process PTA presented a more refined microstructure, possibly due to the low dilution rate. We also conclude that the presence of phases identified as $\mathrm{Y}-\mathrm{Fe}$ and $\mathrm{Y}-\mathrm{Ni}$ led to an increase in dilution rate of the GTAW processes.
\end{abstract}

Key words: Gas tungsten arc welding (GTAW), plasma transferred arc (PTA), wear resistance, phase $\mathrm{Y}$-Fe, phase $\mathrm{Y}-\mathrm{Ni}$.

\section{INTRODUCTION}

The industry currently suffer the effects of various mechanisms of wear in the surface of the pieces, generally characterized by friction, which enables increasing the process of preventive maintenance and recovery equipment. Aiming to extend the life of parts and reduce costs with the same exchange, periodic repairs welding deposition of coatings on most worn areas, has been an important alternative in maintenance.

Research on new materials and updated manufacturing processes of surface coating has sought to address this problem, since the tendency is to use quality alloys to generate the formation of carbides and nitrides, to remedy this deficiency as reported (Midha. et al., 2001). Thus, a major breakthrough for the application of gas tungsten arc welding (GTAW) welding process or the realization of hard coatings based on the use of alloys in the form of powder deposited on the weld pool has been proposed. For both devices must be adapted welding torch that allows obtaining these hard coatings by depositing alloys in powder form.

Despite this difficulty in preparing satisfactory even with the use of different alloy compositions, substrates and results of the welding parameters are obtained. The use of Stellite 6 alloy powder or in the form of rods, have 
Table 1. Comparison between current processes PTA and GTAW as related by D'Oliveira et al. (2008).

\begin{tabular}{lll}
\hline Variables & GTAW & PTA \\
\hline Deposition of alloys & Powder & Powder \\
surface finish & Good & Good \\
Deposition rate & Low - Rod And Powder & High \\
Dilution & High & Low \\
Porosities & Absence & Absence \\
Inclusions & Absence & Absence \\
Gas system & Protection & Gas complex system protection, drag and plasma \\
Gas consumption & 7 L/min & 20 L/min \\
\hline
\end{tabular}

Table 2. Values of the welding parameters to determine the ideal flow of protection gas.

\begin{tabular}{lccc}
\hline Combined parameters & \multicolumn{3}{c}{ Range of variation } \\
\hline Welding current - A & 130 & 150 & 180 \\
Welding speed -cm/min & 10 & 12 & 15 \\
Flow of protection gas-L/min & 5 & 10 & 15 \\
\hline
\end{tabular}

Table 3. Parameter values used to determine the minimum flow of the carrier gas and powder feed rate.

\begin{tabular}{lccc}
\hline Combined parameters & \multicolumn{3}{c}{ Range of variation } \\
\hline Welding current - A & 130 & 150 & 180 \\
Welding speed -cm/min & 10 & 12 & 15 \\
Flow of carrier gas-L/min & $1.0 ; 1.5 ; 2.0$ & $1.0 ; 1.5 ; 2.0$ & $1.0 ; 1.5 ; 2.0$ \\
Powder feed rate -g/min & $9.5 ; 14 ; 19$ & $9.5 ; 14 ; 19$ & $9.5 ; 14 ; 19$ \\
\hline
\end{tabular}

been studied in the deposition of coatings chemical composition in its neat or with the addition of other elements, in an attempt to improve the properties of the coatings. The performance of these properties is directly related to the process parameters such as the intensity of the welding current, which has a direct influence on the microstructure and dilution according to Pradeep et al., 2010). Table 1 shows a graph theoretical comparison between the current processes when applied in coating operations.

This work aims to develop an adaptive to a GTAW welding torch, capable of producing hard coatings with deposition of the alloy in powder form, directly into the weld puddle device. In order to verify the viability applying this procedure, the results will be compared with the usual PTA process, using the approximate inclusive as reported in Madadi et al. (2012).

\section{MATERIALS AND METHODS}

\section{Ideal flow protection gas}

To determine the ideal flow rate protection gas tests were performed with deposition welding speeds ranging from 10 to 15 $\mathrm{cm} / \mathrm{min}$ and welding currents ranging 130-180 A. For these parameters we used a gas flow 5-15 L/min, where it was observed to protect the weld puddle to solidify without the occurrence of visually observable defects, even with the increased flow followed by the increase in current and welding speed. Table 2 shows the parameters used to determine the ideal flow of shielding gas to achieve the coatings.

\section{Flow ideal carrier gas and powder feed rate of metallic}

The determination of these values was analyzed considering that the flow value for the carrier gas should be at least possible and sufficient to drive all the metal powder to puddle without causing instability of the arc and weld puddle. The feed rate was varied to between 9.5 and $19 \mathrm{~g} / \mathrm{min}$ with a gas flow as shown Table 3 and verified the fusion of material deposited to track current and welding speed mentioned above.

\section{Preparation of coating substrates}

As substrate we used the SAE 1020 steel, machined dimensions $120 \times 50 \times 12 \mathrm{~mm}$ and were later rectified to remove oxides, oil and dirt was used as the filler material, a cobalt alloy commercially known as STELLITE 6 powder form and with a particle size around 45 and $180 \mu \mathrm{m}$ and specification of hardness between 390 and 470 
Table 4. Composition of the nominal substrate (SAE 1020) and filler material (STELLITE 6).

\begin{tabular}{lllllllllllll}
\hline & Co & Fe & C & Cr & Ni & W & Si & Mo & Mn & P & S & Others \\
\hline SAE 1020 & - & Bal. & 0.19 & - & - & - & - & - & 0.4 & 0.03 & 0.04 & - \\
STELLITE 6 & Bal. & 2.13 & 1.13 & 30.85 & 2.39 & 4.65 & 1.40 & 0.35 & 0.25 & 0.005 & 0.006 & 0.40 \\
\hline
\end{tabular}

Table 5. Parameters used in the processes GTAW.

\begin{tabular}{lll}
\hline Continuous current & GTAW1 $* * *$ & GTAW2 *** \\
\hline Current - A & 155 & \\
Amplitude - mm & 15 & \\
Distance between pass - mm & 4 & \\
Welding speed - cm/min & 10 \\
Shielding gas flow - Lpm & 10 & \\
Carrier gas flow - Lpm & 1.5 & \\
Distance electrode to workpiece - mm & 10 & \\
Sharpening the electrode tip & $30^{\circ}$ & \\
Distance nozzle to the piece - mm & 13 & 1.0 \\
Speed feed - rpm & 0.5 & 19 \\
Deposition rate - g/min & 9.5 & \\
\hline
\end{tabular}

P.S. * Automatic ** Semiautomatic.

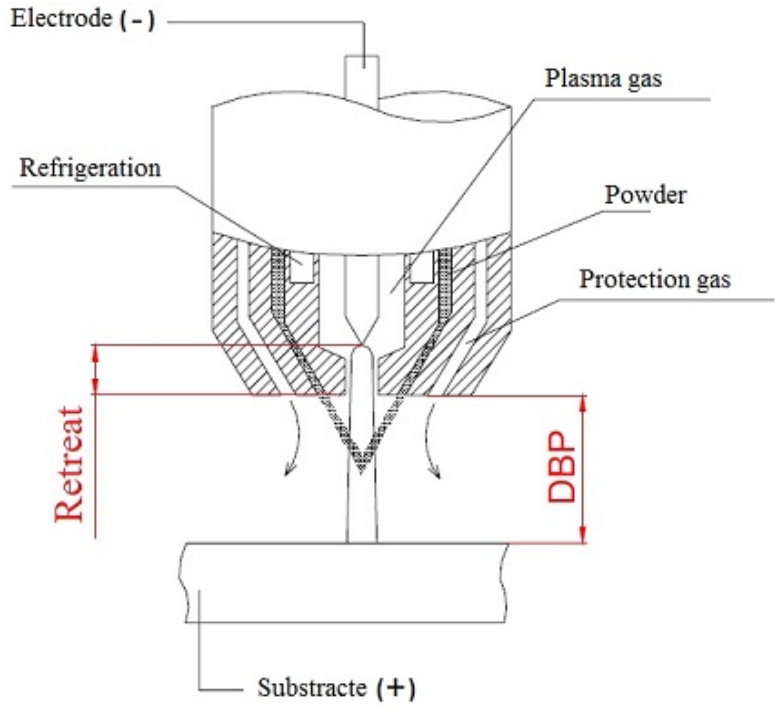

Figure 1. Schematic representation of the process PTA according to Balasubrarnanian et al. (2009).

HV. Table 4 shows the nominal chemical composition of the substrate and the alloy STELLITE 6, supplied by the manufacturer. For deposition of metal powder was used automatic and semiautomatic feeding system type ADP-2, and the deposition controlled by adjusting the speed of a toothed wheel that directs the powder into a chamber, where the supply line will be aided by a gas drag. For the purpose of comparing the processes PTA and GTAW with powder deposition welding electrical parameters used are shown in Table 5.

The weld beads were performed by a central welding INVERSAL
450 a device which enables the execution of all processes of arc welding. Each plate was deposited on a cord with the development of a welding torch displacement in the form of arc oscillation amplitude of $15 \mathrm{~mm}$ and advancement of $4 \mathrm{~mm}$, by an automated system called Tartilope model WELDING V2/IMC. Figure 1 shows the device for applying the coating process by PTA and Figure 2 by GTAW, developed and adapted to deposit the alloy torch directly on the weld pool.

Figure 3 shows a photo of the whole nozzle/nozzle device driver to adapt the GTAW torch after preliminary test coating, where it can be observed that there was no adherence of the material in both the driver as the electrode tip. Figure 4 shows the prototype adapted to GTAW torch with 8 holes as the previous Figure 3. For the effective operation of the device was needed an additional system for cooling water and an automatic system for feeding the powder, which satisfied the GTAW and PTA processes. The GTAW process weld deposits showed good quality depending on the alloy (powder), but always on the basis of low deposition rates, the device had to control automatically.

\section{Characterization of coatings}

\section{Visual inspection}

The coatings were analyzed by simple observation the eye, with the intention to qualitatively assess the overall surface finish to the determination of discontinuities that could cripple the procedure, such as: porosity, cracks, longitudinal and transverse to the weld cords.

\section{Metallographic analysis}

The methodology to evaluate the coatings was proceeded through qualitative visual analysis macrografics cross sections of the cords and microstructural analysis. The microstructural analysis was 


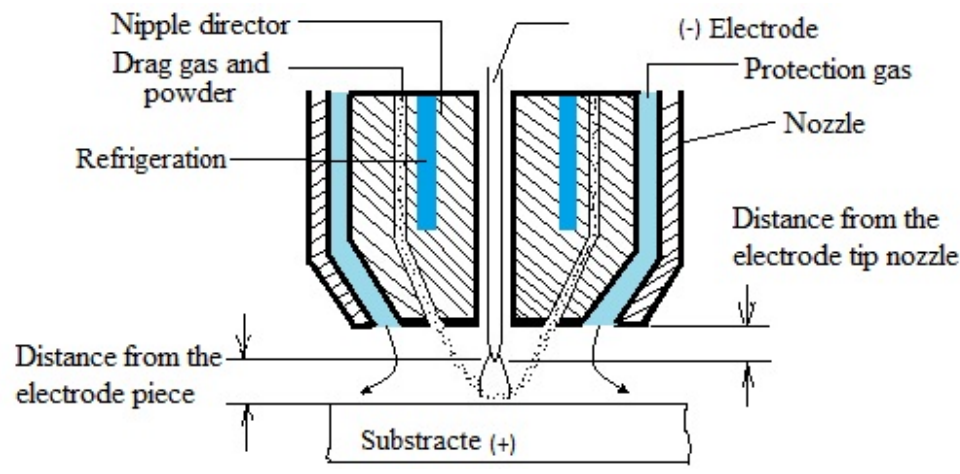

Figure 2. Schematic representation of the device for powder deposition process by GTAW studied.

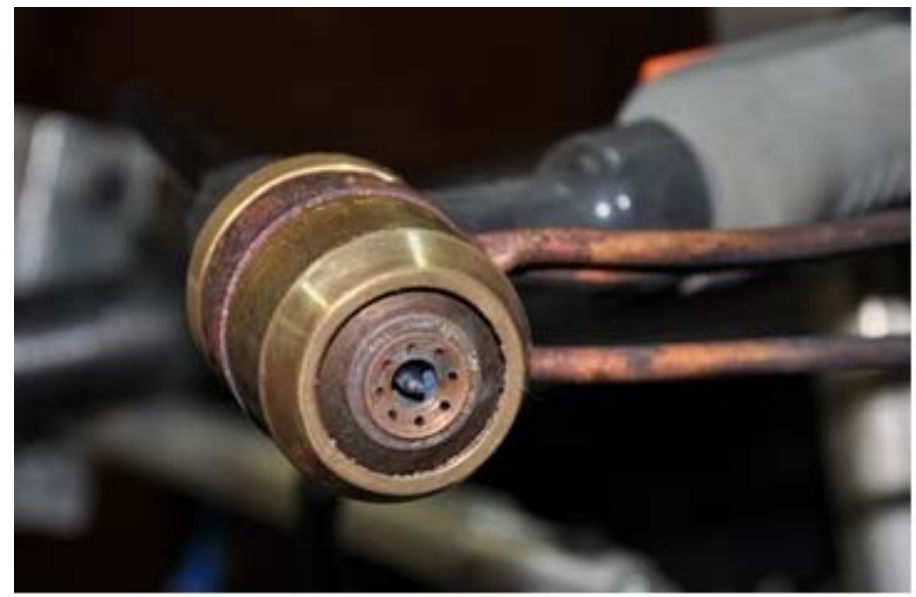

Figure 3. Photo of the bottom view of the torch adapted test after deposition.

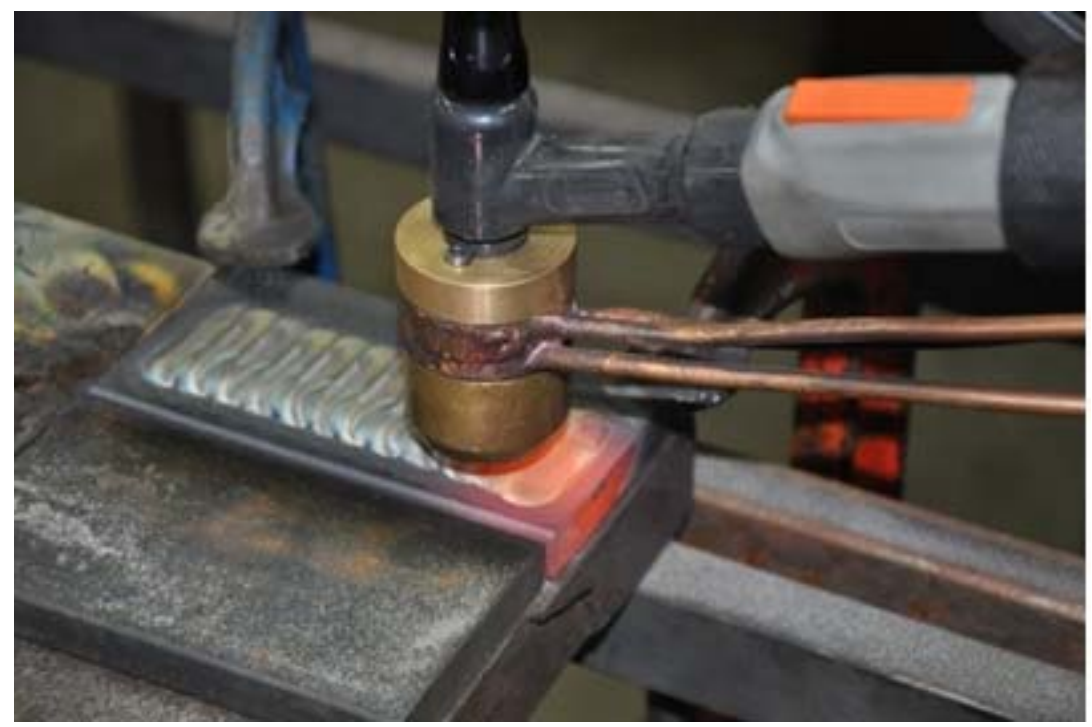

Figure 4. Photo of the device after the operation, configuration concentric with 8 holes, adapted to the torch GTAW/PTA with deposition automatic. 

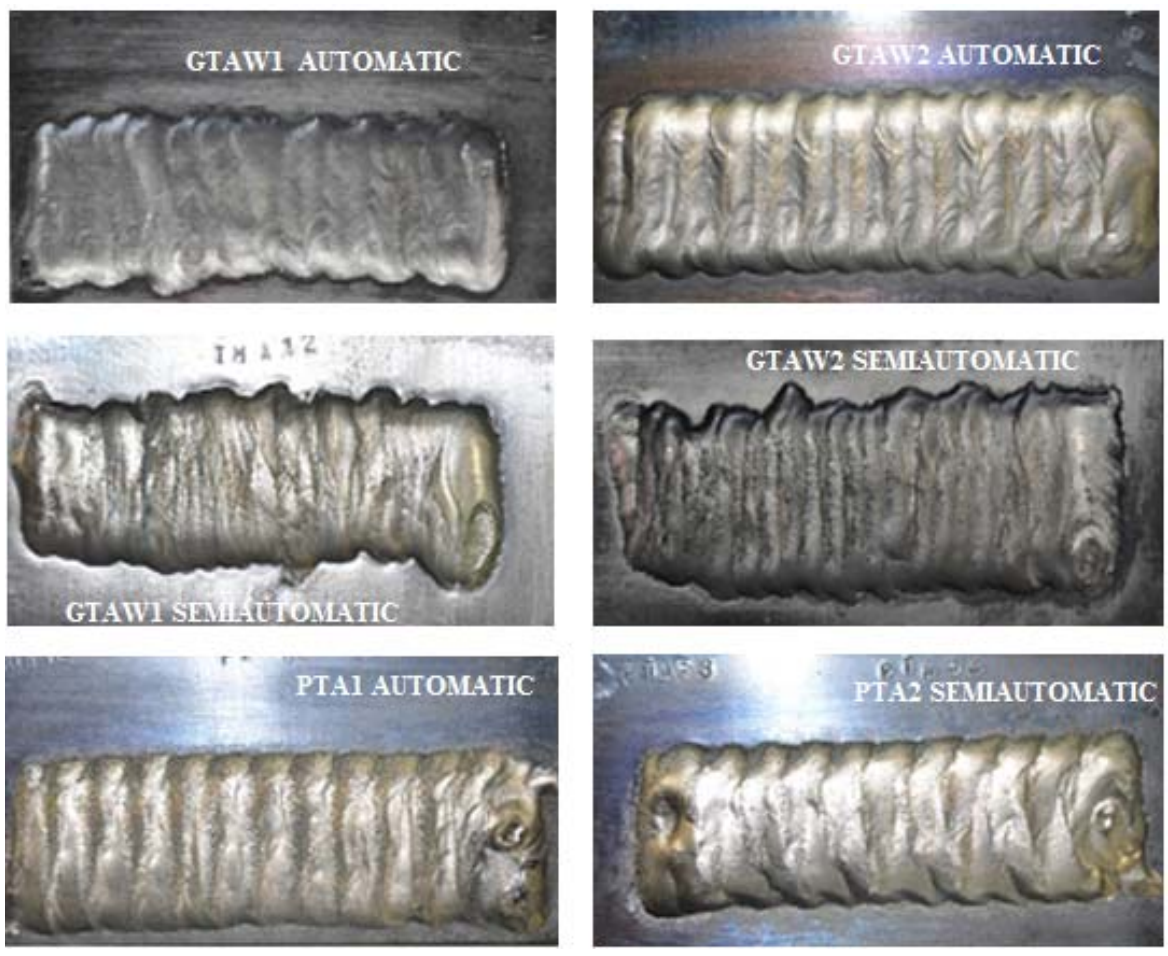

Figure 5. Photos cords deposited (surface view) - GTAW and PTA automatic and semiautomatic respectively.

carried out in KOZO metallographic microscope, model XVM 300 digital camera with DCM 510, on surfaces and in the regions of the interface between the coating and substrate, and the attacks to disclosure were made in specific solution based alloys Cobalt, consisting of: $15 \mathrm{ml} \mathrm{H}_{2} \mathrm{O}, 15 \mathrm{ml} \mathrm{HNO}, 15 \mathrm{ml}$ of $\mathrm{CH}_{3} \mathrm{COOH}$ and 60 $\mathrm{ml}$ of $\mathrm{HCl}$ according to Madadi et al. (2011).

\section{Determination of the dilution}

The quantification of the dilution of the cords was made by the method of area ratio based on participation of the substrate to form the coating using the Digital Image Tool for calculating and delineation of the areas. The higher the dilution, the more the properties of the coatings are distant from the nominal properties of the alloy. Thus we tried to keep the dilution in the lowest level possible while obtaining a proper metallurgical bonding to the coating, whereas an increase in the dilution causes a decrease in the hardness of the deposit, and this in turn increases the wear volume to deposit diluted as Bond and D'Oliveira (2012). On the other hand it is known that dilution is influenced by the arc current, the deposition rate, speed of the torch, the arc length and frequency of oscillation of the torch second (Balasubrarnanian et al., 2009).

\section{$X$-ray diffraction analysis}

The X-ray analysis were conducted on the Diffractometer Model Rotaflex Rigaku RU 200B X-ray Laboratory of Crystallography Group of the IFSC USP São Carlos used to determine the spectra of all tested variations of deposition. The scan parameters of the electron beam that is, speed and scan range was 2-Theta $(0)$ and monitored with software "Match - Phase Identification from Powder Diffraction".

\section{RESULTS AND DISCUSSION}

\section{Visual analysis}

Figure 5 shows the surface appearance of strings of all variations generated where the cords showed a good surface finish (roughness), but with different widths and heights in relation to manual. However, as shown in the literature, the PTA processes (D'Oliveira et al., 2008) have lower dilutions for the same deposition rate, but the deposition proceeds similar to GTAW, which shows characteristics similar to visual PTA and both have good wettability and free of cracks. But PTA process has a better surface finish taking into account only the roughness.

For comparison among the processes PTA - Powder (PTA) and GTAW - Powder (GTAW), welding parameters used are showed in Table 2, where the number 1 correspond to $9.5 \mathrm{~g} / \mathrm{min}$ dilution rate and the number 2 the rate of $19 \mathrm{~g} / \mathrm{min}$. Table 3 shows the analysis results of dilution and calculation of income for the deposition processes PTA, GTAW1 and GTAW2 automatic and semiautomatic (Table 6).

However, as shown in the literature, the process introduces PTA lowest dilution even by varying the deposition rate of metallic powder, but with yields similar deposition. Analyzing only the cords deposited by GTAW there is a considerable reduction of dilution, when increasing the deposition rate, reaching values near the 
Table 6. Deposition efficiency and dilution of coatings.

\begin{tabular}{lcccccc}
\hline Variables & PTA1 $^{*}$ & PTA2 $^{*}$ & GTAW1 $^{*}$ & GTAW2 $^{*}$ & GTAW1 $^{* *}$ & GTAW2 $^{* *}$ \\
\hline Deposition rate g/min & 9.5 & 19 & 9.5 & 19 & 9.5 & 19 \\
Efficiency to diluition(\%) & 93 & 93 & 94 & 87 & 85 & 85 \\
Diluition(\%) & 7.0 & 4.2 & 17.4 & 7.0 & 10.0 & 5.0 \\
\hline
\end{tabular}

P.S. * Automatic, ${ }^{*}$ Semi-automatic.

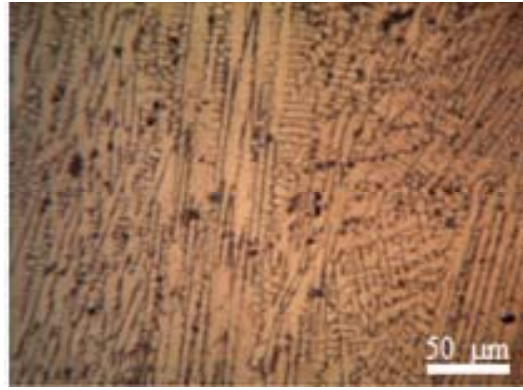

(a)

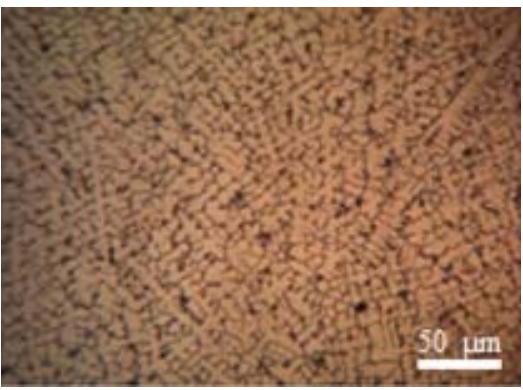

(b)

Figure 6. Photomicrographs of the powder coating GTAW1 (a) close to the interface and (b) near the surface.

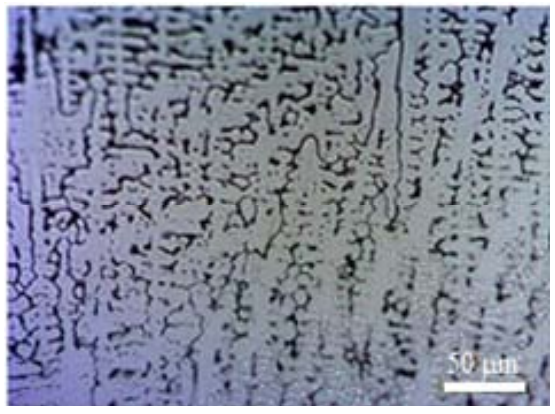

(a)

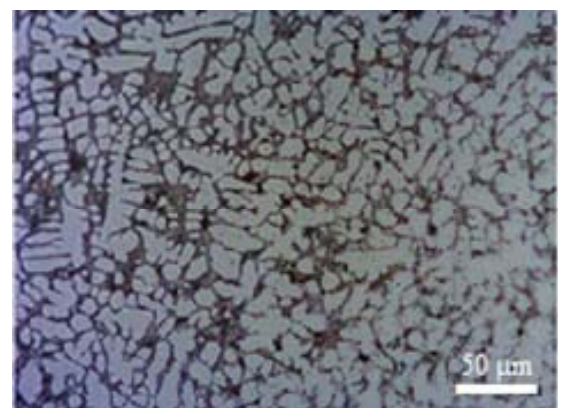

(b)

Figure 7. Photomicrographs of the powder coating PTA1 (a) close to the interface and (b) near the surface.

PTA. This observation is in agreement with that found in the literature, or the higher the deposition rate for the same level of energy, less dilution as reported by Balasubrarnanian et al. (2009). The low dilution procedure manual or semi-automatic may be due to another factor, namely, the non-constant speed in the welding for example.

\section{Micrographic analysis}

Figures 6 and 7 show micrographs of deposits made near the interface of coating/substrate and the coating surface in both cases. It is noted that the micrographs are similar to results obtained in Kashani et al. (2008) and Hou et al. (2007) which are more refined structures near the surface and melting in the region close to where there is a growing dendritic growth followed by a planar microstructure featuring a hipoeutetic. Still comparing the coatings was observed carefully with the deposit PTA showed a more refined microstructure, perhaps due to the low dilution caused by the process second (Fei et al., 2006).

\section{X-ray diffraction analysis}

Figures 8,9 , and 10 show diffraction patterns of the 


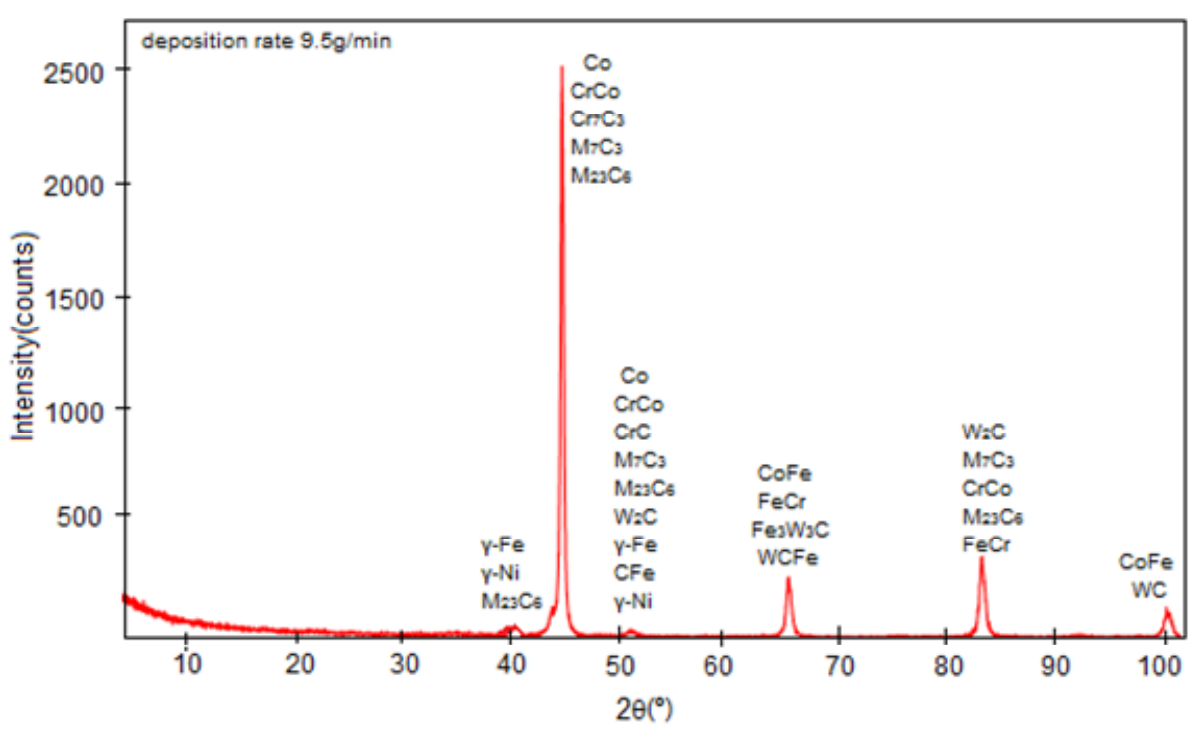

(a)

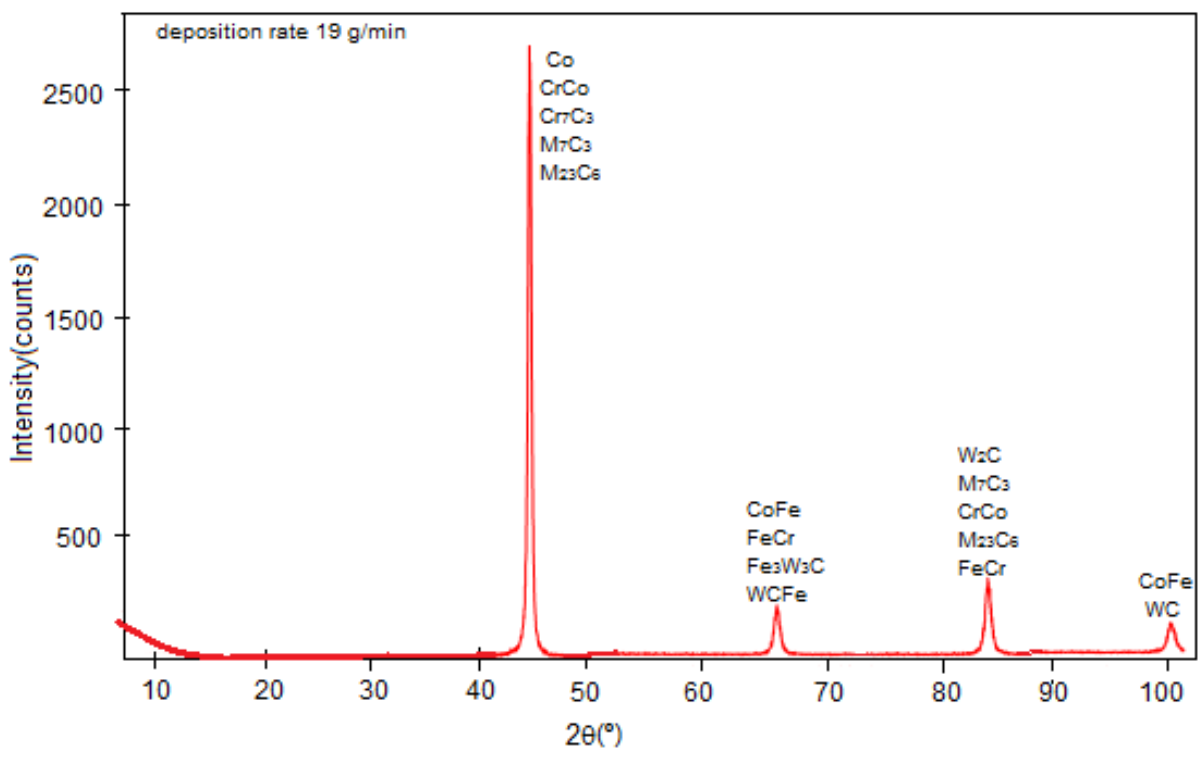

(b)

Figure 8. Diffractogram of the GTAW process automatic: (a) deposition rate $9.5 \mathrm{~g} / \mathrm{min}$, (b) deposition rate $19 \mathrm{~g} / \mathrm{min}$.

deposition made by automatic GTAW, semi-automatic GTAW and PTA process, with rates of 9.5 and $19 \mathrm{~g} / \mathrm{min}$ respectively. It was observed that the diffractometric analysis of the cords presented spectrum similar but not identical, and that the deposits made by the device in both cases, where there was the appearance of $\mathrm{Cr}$-rich carbides transform from $\mathrm{M}_{7} \mathrm{C}_{3}$ to $\mathrm{M}_{23} \mathrm{C}_{6}$ in a Co-Cr-W-C Stellite 6 alloy as related (Shin et al., 2003) and phases identified as $\mathrm{y}-\mathrm{Fe}, \mathrm{y}-\mathrm{Ni}$ as shown in Figures $8 \mathrm{a}$ and $9 \mathrm{a}$, especially in the automatic GTAW process.
These phases only appeared for the GTAW process and the low deposition rate $(9.5 \mathrm{~g} / \mathrm{min})$, which led to higher values of deposition rate. However, for the semiautomatic GTAW process such developments occur for two deposition rates 9.5 and $19 \mathrm{~g} / \mathrm{min}$, perhaps because the movement of the torch ensued manually with some overlaps passes.

Nevertheless, if we consider that the diffraction pattern of Figure 10 reflects the analysis of a region where the first pass was performed by the operator, so may have 


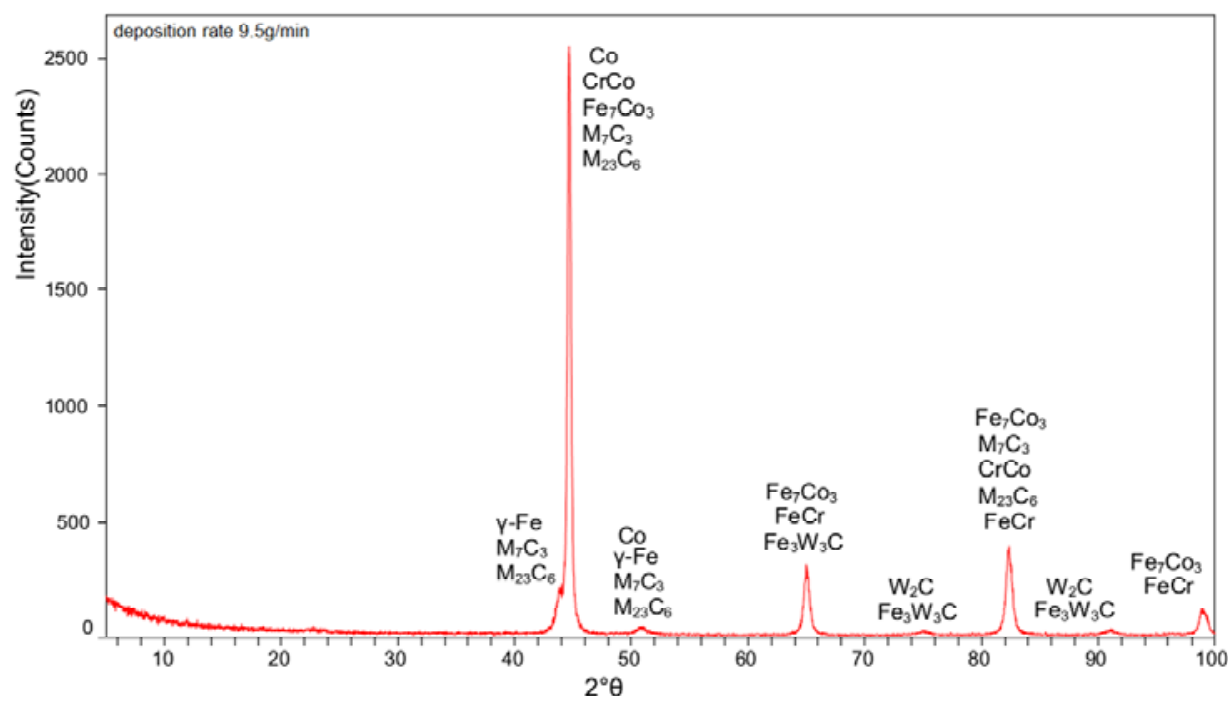

(a)

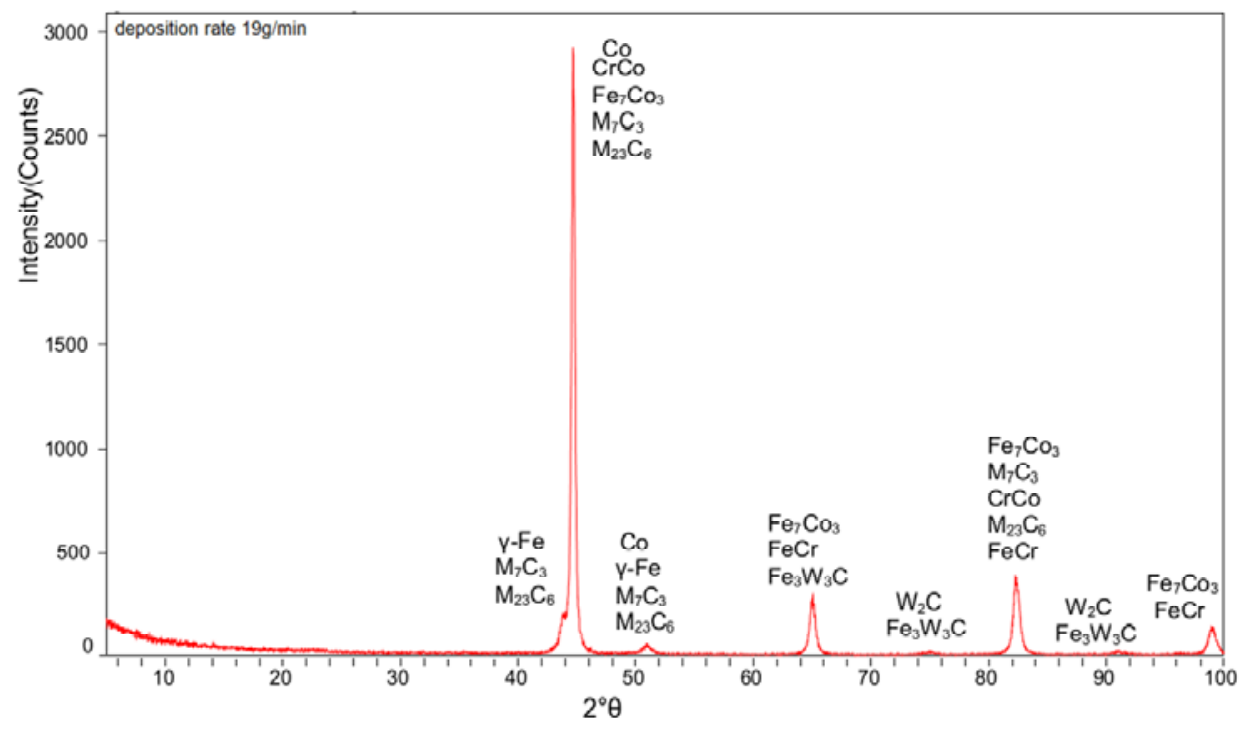

(b)

Figure 9. Diffractogram of the GTAW process semi-automatic: (a) deposition rate $9.5 \mathrm{~g} / \mathrm{min}$, (b) deposition rate19 $\mathrm{g} / \mathrm{min}$.

occurred at this point greater dilution was inhibited by the second pass as Cinca and Guilemany (2013).

\section{Conclusions}

As the main objective was to develop a device to torch GTAW process for producing a hardfacing and so detects that its performance is very similar to that just PTA process, that is, the hard coating with properties almost similar. However, we observed that the diffractometric analysis of the cords presented spectrum near, but that the deposits made by the device in both cases, where there was the appearance of phases identified as $\mathrm{y}-\mathrm{Fe}, \mathrm{Y}$ $\mathrm{Ni}$. These phases are appeared for the GTAW process and the low deposition rate, which led to higher values of dilution rate characteristic of this device.

However, for the semi-automatic GTAW process such developments occur for two deposition rates 9.5 and 19 $\mathrm{g} / \mathrm{min}$, perhaps because the movement of the torch ensued manually with some overlaps passes. Therefore, it is thought that with improved GTAW process parameters, such as: increasing the deposition rate by increasing the speed or decreasing the welding current 


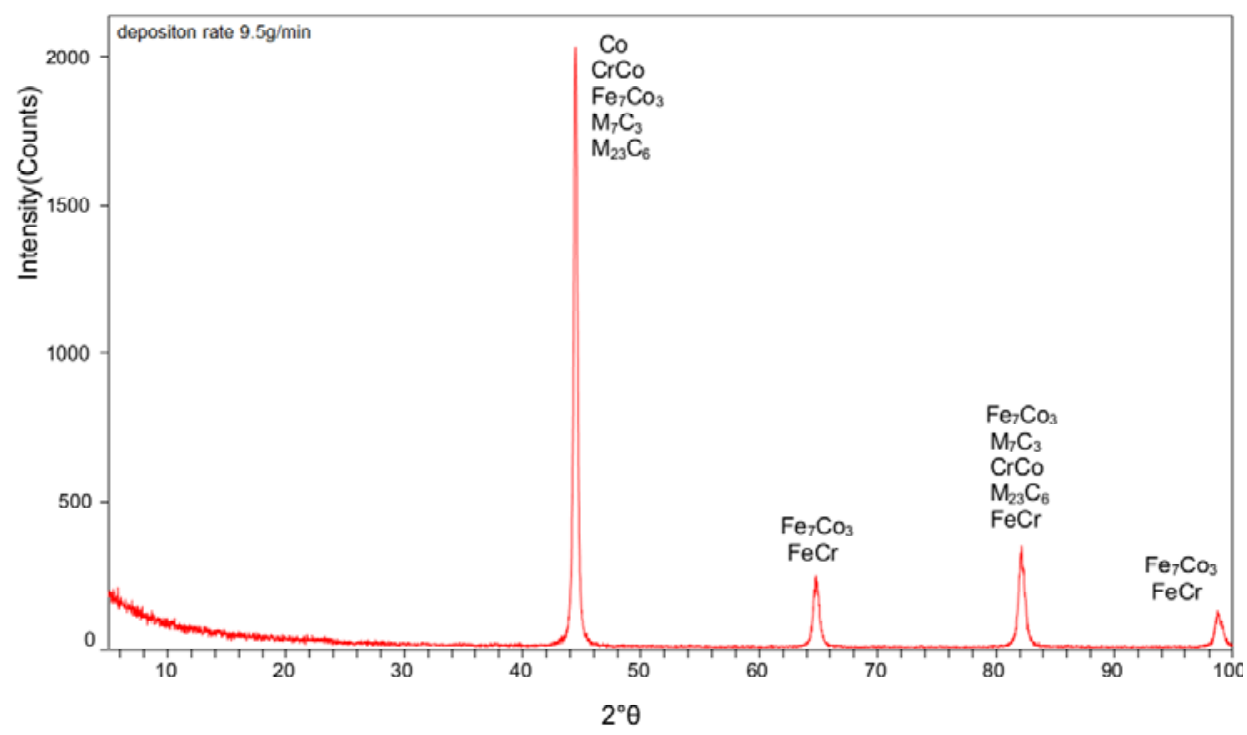

(a)

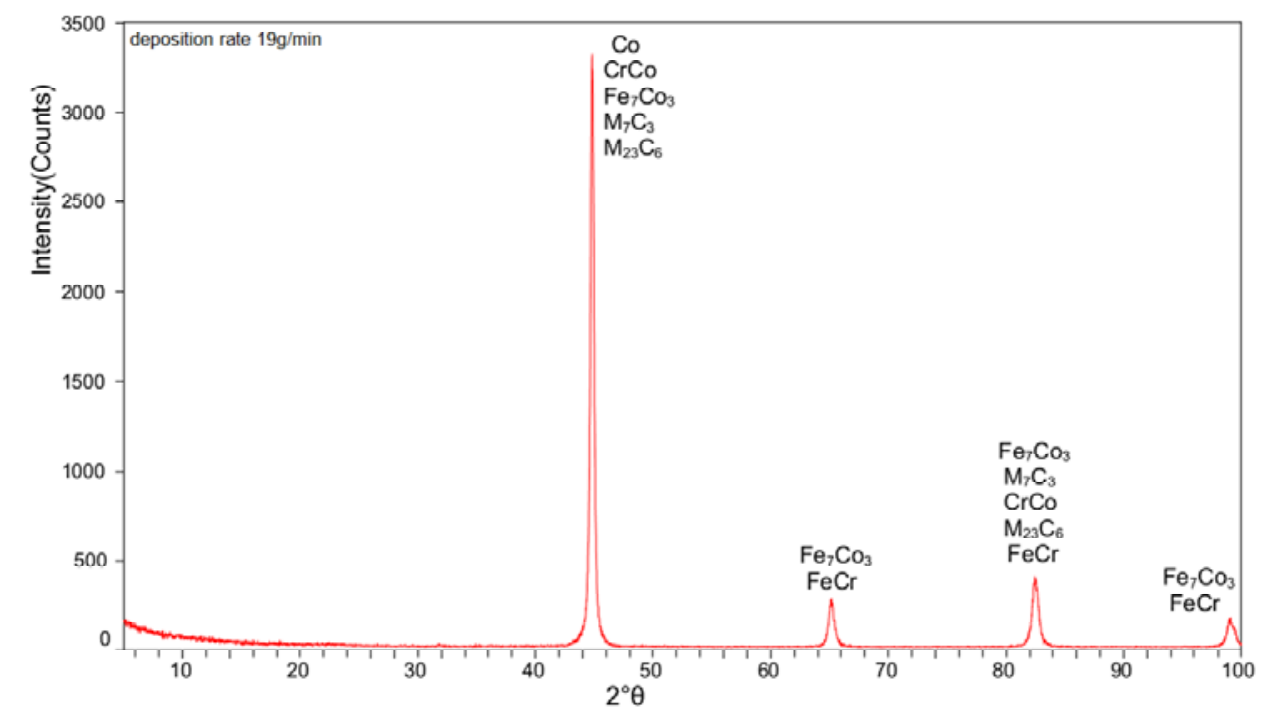

(b)

Figure 10. Diffractogram of the GTAW process PTA: (a) deposition rate $9.5 \mathrm{~g} / \mathrm{min}$, (b) deposition rate $19 \mathrm{~g} / \mathrm{min}$.

value and considering its lower cost compared to PTA, the process was more important for operational and protective coatings purposes.

\section{Conflict of Interest}

The author(s) have not declared any conflict of interests.

\section{ACKNOWLEDGMENTS}

The Department of Mechanical Engineering at USP - São
Carlos and his entire team of technicians and the Departments of Materials and Manufacturing UTFPR Federal Technological University of Paraná - Cornelio Procópio - PR.

\section{REFERENCES}

Balasubrarnanian V, Lakshminarayanan AK, Varahamoorthy R, Babu S (2009). Application of Response Surface Methodolody to Prediction of Dilution in Plasma Transferred Arc Hardfacing of Stainless Steel on Carbon Steel. J. Iron Steel Res. Int. 16(I):44-53. http://dx.doi.org/10.1016/S1006-706X(09)60009-1

Bond D, D'Oliveira ASCM (2012). Effect of Current and Atomized Grain 
Size Distribution on the Solidification of Plasma Transferred Arc Coatings. Mater. Res. 15(5):770-774 http://dx.doi.org/10.1590/S1516-14392012005000101

Cinca N, Guilemany JM (2013). Cold Gas Sprayed Stellite-6 Coatings and their Wear Resistance; J. Mater. Sci. Eng. 2(2):1-6.

D'Oliveira ASCM, Cristo A, Vaz D (2008). Evaluation of intermetallic coatings processed by PTA. In: International Thermal Spray Conference, aastricht. ITSC Moving Borders CD-ROM:1090-1094.

Fei YH, Zao YY, Li HC, Truan SL (2006). Microstructural characteristics of PTA-Over layed $\mathrm{NbC}$ on pure Ti. Surf. Coat. Technol. 200(24):6881-6887. http://dx.doi.org/10.1016/j.surfcoat.2005.10.021

Hou Q, Huang Z, Gao J (2007). Effects of Y2O3 on the microstructure and wear resistance of cobalt-based alloy coatings deposited by plasma transferred arc process. Rare Metals. 26(2):103-109. http://dx.doi.org/10.1016/S1001-0521(07)60168-5

Kashani $H$, Sadeghi Laridjani M, Amadeh A, Khodagholi $M$, Ahmadzadeh S (2008). The influence of volumetric dilution on the strain induced $Y$ for $\varepsilon$ martensitic transformation in GTAW processed Co-Cr-Mo alloy. Mater. Sci. Eng. A. 478:38-42. http://dx.doi.org/10.1016/j.msea.2007.05.061

Madadi F, Ashrafizadeh F, Shamanian M (2011). Effect of pulse current on microstructure and wear resistance of Stellite6/tungsten carbide claddings produced by tungsten inert gas process. Surf. Coatings Technol.

http://dx.doi.org/10.1016/j.surfcoat.2011.03.076
Madadi F, Ashrafizadeh F, Shamanian M (2012). Optimization of pulsed TIG cladding process of stellite alloy on carbon steel using RSM; J. Alloys Comp. 510:71-77 http://dx.doi.org/10.1016/j.jallcom.2011.08.073

Midha S, Ong HS, Poh LS, Cheang P (2001) Intermetallic coatings produced by TIG surface melting. J. Mater. Process. Technol. 113:516-520. http://dx.doi.org/10.1016/S0924-0136(01)00609-4

Pradeep GRC, Ramesh B, Durga P (2010). A review paper on hardfacing processes and materials. Int. J. Eng. Sci. Technol. 2(11):6507-6510.

Shin JC, Doh JM, Yoon DY, Kim JS (2003). Effect of molybdenum on the microstructure and wear resistance of cobalt-base Stellite hardfacing alloys. Surface Coatings Technol. 166(2-3):117-126. http://dx.doi.org/10.1016/S0257-8972(02)00853-8 